\title{
PERAN PENYULUH DALAM PENERAPAN INTENSIFIKASI MINAPADI UNTUK MENDUKUNG KEMANDIRIAN PANGAN PETANI
}

\section{THE ROLE OF EXTENSION WORKERS IN THE APPLICATION OF MINAPADI INTENSIFICATION TO SUPPORT FARMER'S FOOD INDEPENDENCE}

\author{
Dede Tatang $*^{1}$, Muhamad Nurdin Yusuf ${ }^{1}$, Agus Yuniawan Isyanto ${ }^{1}$ \\ ${ }^{1}$ Fakultas Pertanian, Universitas Galuh \\ *Email : dedetatang001@gmail.com
}

\begin{abstract}
ABSTRAK
Penelitian ini bertujuan untuk mengetahui: 1). peran penyuluh dalam pendampingan program intensifikasi minapadi; 2). tingkat penerapan program intensifikasi minapadi; dan 3). Faktor-faktor yang berpengaruh terhadap tingkat penerapan intensifikasi minapadi pada Kelompoktani Mulyasari di Desa Arjasari Kecamatan Leuwisari Kabupaten Tasikmalaya. Jenis penelitian ini adalah penelitian deskriptif analitis dengan metode studi kasus. Pengambilan responden dilakukan dengan menggunakan metode sensus kepada 45 orang anggota Kelompoktani Mulyasari. Data primer dan data sekunder dikumpulkan melalaui observasi, wawancara, studi literatur dan dokumentasi. Peran penyuluh dan intensifikasi minapadi dianalisis secara deskriptif dan untuk mengetahui pengaruhnya dianalisis dengan regresi linear berganda. Hasil penelitian menunjukkan bahwa 1). peran penyuluh dalam melakukan pendampingan intensifikasi minapadi berada pada kategori berperan; 2) intensifikasi komponen inti minapadi berada pada kategori selalu diterapkan; 3). faktor yang berpengaruh terhadap intensifikasi minapadi pada Kelompoktani Mulyasari Desa Arjasari Kecamatan Leuwisari Kabupaten Tasikmalaya adalah umur, tingkat pendidikan, pendapatan, luas lahan, dan akses ke pasar output. Sementara faktor peran penyuluh, pengalaman, jumlah keluarga, keikutsertaan dalam kelompoktani dan akses ke pasar input tidak memberikan pengaruh nyata.
\end{abstract}

Kata kunci: peran penyuluh, intensifikasi minapadi, kemandirian pangan.

\begin{abstract}
This study aimed to find out: 1). the role of extension workers in mentoring minapadi intensification programs; 2). the level of application of the Minapadi intensification program; and 3). Factors that influence the level of application of Minapadi intensification in the Mulyasari Farmers Group in Arjasari Village, Leuwisari District, Tasikmalaya Regency. This type of research was analytical descriptive research with a case study method. Respondents were taken using the census method for 45 members of the Mulyasari Farmer group. Primary and secondary data were collected through observation, interviews, literature studies and documentation. The role of extension agents and minification intensification was analyzed descriptively and to determine the effect was analyzed by multiple linear regression. The results showed that 1). the role of the instructor in conducting minification intensification mentoring was in the already playing category; 2) intensification of core core components in the always applied category; 3). Factors that influence the intensification of minapadi in the Mulyasari Kelompoktani Arjasari Village, Leuwisari District, Tasikmalaya Regency were age, education level, income, land area, and access to output markets. While the role of extension agents, experience, number of families, participation in family groups and access to input markets did not have a real effect
\end{abstract}

Key Words : the role of extension workers, intensification of minapadi, food independence 
PENDAHULUAN

Undang-undang Nomor 18 Tahun 2012 tentang Pangan, mengartikan kemandirian pangan sebagai kemampuan negara dan bangsa dalam memproduksi pangan yang beraneka ragam yang dapat menjamin pemenuhan kebutuhan pangan yang cukup sampai di tingkat perseorangan dengan memanfaatkan potensi sumber daya alam, manusia, sosial, ekonomi, dan kearifan lokal secara bermartabat. kemandirian pangan pada dasarnya mengandung makna makro dan makna mikro. Makna makro terkait dengan penyediaan pangan di seluruh wilayah setiap saat, sedangkan makna mikro terkait dengan kemampuan setiap warga dalam memanfaatkan potensi sumber daya alam, manusia, sosial, ekonomi, dan kearifan lokal secara bermartabat.

Mewujudkan kemandirian pangan skala rumah tangga harus dilakukan bersama antara pemerintah pusat dan daerah dalam rangka pemenuhan kebutuhan dasar masyarakat yang memberikan manfaat secara adil, merata, dan berkelanjutan yang tercermin dari ketersediaan pangan yang cukup, baik jumlah maupun mutunya, aman, merata dan terjangkau bagi setiap warga masyarakat. Kabupaten Tasikmalaya harus mampu menggali dan mengenal potensi wilayah yang dimiliki demi tercapainya kemandirian pangan dan kesejahteraan bagi masyarakatnya.

Sampai saat ini, upaya perwujudan kemandirian pangan umumnya dihadapkan pada berbagai kendala, antara lain: jumlah penduduk yang terus meningkat, kerusakan lingkungan, perubahan iklim, terbatasnya infrastruktur (jaringan irigasi, jalan produksi), belum cukup tersedianya benih/bibit unggul bermutu, pupuk, pakan, pestisida/obat-obatan, alat dan mesin pertanian hingga ke tingkat usahatani, konversi lahan pertanian produktif ke penggunaan non-pertanian yang tidak terkendali, ketergantungan konsumsi beras, kompetisi pemanfaatan air dan status kepemilikan lahan.

Untuk itu diperlukan rumusan strategi dan inovasi teknologi dalam upaya pengelolaan sumberdaya alam secara efektif dari segi ekologi dan efisien dari segi ekonomi. Salah satu teknologi yang dapat diterapkan adalah LEISA (lowexternal input and sustainable agriculture). Sistem ini mengombinasikan komponen tanaman, hewan, tanah, air, iklim, dan manusia dalam sistem produksi agar saling melengkapi dan bersinergi (Das, 2013). Salah satu sistem pertanian terpadu diwujudkan dalam intensifikasi minapadi. Intensifikasi minapadi merupakan suatu 
kegiatan pertanian yang memadukan dikenal masyarakat khususnya di Jawa budidaya ikan dengan budidaya padi sawah Barat seperti Ciamis sejak tahun 1860. (Abuasir, dkk, 2004).

Minapadi mempunyai sejarah yang panjang di Indonesia yaitu dimulai dari abad ke-9 (Surtida, 2000). Diodenha (2011), menyatakan bahwa minapadi telah diterapkan pada tahun 1950-1960-an. Khususnya di Jawa Barat, Nurhayati, dkk, (2016) melaporkan sistem budidaya padi yang dipraktikkan secara luas di lahan irigasi dengan 3 (tiga) macam sistem, yaitu: sistem minapadi, sistem penyelang dan sistem palawija-ikan.

Namun sejatinya, sistem minapadi sudah

Tabel 1. Sentra Produksi Sistem Pertanian Terpadu Minapadi dan Longyam di Kabupaten Tasikmalaya Taun 2018

\begin{tabular}{clrll}
\hline No. & \multicolumn{1}{c}{ Kecamatan } & Luas (Ha) & Pertanian Terpadu & Komoditas \\
\hline 1 & Salawu & 72 & 1.Minapadi & Padi sawah-ikan \\
2 & Tanjungjaya & 58 & & mujair, ikan mas, ikan \\
3 & Manonjaya & & \\
4 & Singaparna lele \\
5 & Mangunreja & 562 & & Ikan-ayam broiler, \\
6 & Sukarame & 95 & 2.Longyam & ayam petelur, ayam \\
7 & Cigalontang & 615 & \\
8 & Leuwisari & 115 & \\
9 & Padakembang & 971 & \\
10 & Sariwangi & 953 & \\
11 & Sukaratu & 235 & \\
12 & Cisayong & 237 & \\
13 & Sukahening & 254 & \\
14 & Ciawi & 98 & \\
15 & Pagerageung & 275 & \\
\hline
\end{tabular}

Sumber : Disperpakan Kabupaten Tasikmalaya, 2019

Kecamatan Leuwisari merupakan wilayah yang paling luas dalam pengembangan sistem pertanian terpadu minapadi dan longyam yaitu seluas 791 hektar. Kecamatan Leuwisari mempunyai luas lahan sawah sebesar 1.146 hektar. Sementara lahan yang sudah digunakan sistem pertanian terpadu baru mencapai 84,72 persen yang terdiri atas sistem minapadi sebesar 394 hektar dan sistem longyam sebesar 397 hektar. Selengkapnya pada Tabel 2. 
Tabel 2. Luas Lahan Sistem Pertanian Terpadu di Kecamatan Leuwisari Tahun 2018

\begin{tabular}{llrrrrrr}
\hline \multirow{2}{*}{ No } & & \multicolumn{2}{c}{ Minapadi } & \multicolumn{2}{c}{ Longyam } & \multicolumn{3}{c}{ Pertanian Terpadu } \\
\cline { 3 - 8 } & & Luas & $\%$ & Luas & $\%$ & Luas & $\%$ \\
\hline 1 & Arjasari & 84 & 30,66 & 76 & 27,74 & 160 & 58,39 \\
2 & Ciawang & 34 & 22,22 & 42 & 27,45 & 76 & 49,67 \\
3 & Jayamukti & 56 & 37,33 & 48 & 32,00 & 104 & 69,33 \\
4 & Linggawangi & 54 & 31,58 & 43 & 25,15 & 97 & 56,73 \\
5 & Linggamulya & 76 & 53,15 & 62 & 43,36 & 138 & 96,50 \\
6 & Cigadog & 55 & 41,35 & 62 & 46,62 & 117 & 87,97 \\
7 & Mandalagiri & 35 & 28,69 & 64 & 52,46 & 99 & 81,15 \\
\hline
\end{tabular}

Sumber : BPP Kecamatan Leuwisari, 2019

Kelompoktani Mulyasari mempunyai lahan sawah seluas 43,00 hektar dengan jumlah anggota sebanyak 129 orang. Namun realisasi lahan sawah yang digunakan untuk intensifikasi minapadi adalah 32,00 hektar yang dikelola oleh 45 petani lebih kecil dari luas lahan garapan yang ada, artinya masih mempunyai potensi untuk dikembangkan dan disebarluaskan, salah satunya melalaui kegiatan penyuluhan yang bertujuan untuk menjamin efektifitas pelaksanaan kegiatan dan keberlanjutan program minapadi,

\section{METODE PENELITIAN}

Jenis penelitian ini adalah penelitian kuantitatif. Tujuannya untuk membuat gambaran secara sistematis, faktual dan akurat mengenai fakta, sifat dan hubungan fenomena yang diselidiki (Sugiyono, 2013). Metode yang digunakan adalah studi kasus. Penelitian kasus adalah suatu penelitian yang dilakukan secara intensif, terinci dan mendalam terhadap organisasi atau gejala yang meliputi daerah atau subjek yang sangat sempit dengan sifat penelitian kasus yang lebih mendalam (Arikunto, 2010).

Indikator intensifikasi minapadi diambil dari Juknis Budidaya Minapadi dari Direktorat Produksi dan Usaha Budidaya KPK Republik Indonesia. Peran penyuluh diambil dari Peraturan Dirjen Perikanan Budidaya Nomor 64/PER-DJPB/2018 tentang Petunjuk Teknis Penyaluran Budidaya Ikan Sistem Minapadi. 
Tabel 3. Operasionalisasi Intensifikasi Minapadi

\begin{tabular}{|c|c|c|c|c|c|c|}
\hline $\begin{array}{l}\text { Vari } \\
\text { abel }\end{array}$ & $\begin{array}{c}\text { Definisi } \\
\text { Operasional }\end{array}$ & & Indikator & & Item & $\begin{array}{c}\text { Skala } \\
\text { Pengukuran } \\
\end{array}$ \\
\hline \multirow[t]{7}{*}{$\begin{array}{l}\text { Intensi } \\
\text { fikasi } \\
\text { Minap } \\
\text { adi }\end{array}$} & $\begin{array}{l}\text { Usaha } \\
\text { untuk } \\
\text { meningkatk } \\
\text { an hasil } \\
\text { dengan cara } \\
\text { meningkatk } \\
\text { an } \\
\text { kemampua } \\
n \text { atau }\end{array}$ & 1) & Persiapan lahan & $\begin{array}{l}\text { 3) } \\
\text { 4) }\end{array}$ & $\begin{array}{l}\text { Melakukan pengolahan tanah dua } \\
\text { kali } \\
\text { Menggunakan lebar dasar pematang } \\
40 \mathrm{~cm} \text {, lebar atas } 30 \mathrm{~cm} \text {, tinggi } 40 \\
\mathrm{~cm} \\
\text { Membuat parit pembatas } \\
\text { Melakukan pemupukan dasar }\end{array}$ & Ordinal \\
\hline & $\begin{array}{l}\text { memaksima } \\
\text { lkan } \\
\text { produktivita } \\
\text { s faktor } \\
\text { faktor } \\
\text { produksi } \\
\text { yang telah } \\
\text { ada melalui } \\
\text { teknik } \\
\text { budidaya } \\
\text { padi dan } \\
\text { ikan pada } \\
\text { lahan yang } \\
\text { sama }\end{array}$ & 2) & $\begin{array}{l}\text { Pembuatan } \\
\text { Wadah Minapadi } \\
\text { (caren) }\end{array}$ & 1) & $\begin{array}{l}\text { ukuran kobakan minimum } 1,5 \mathrm{x} \\
1,5 \mathrm{x} 0,5 \mathrm{~m} \\
\text { Luasan petakan sawah minimal } 500 \\
\mathrm{~m}^{2} \\
\text { Pematang harus kuat untuk } \\
\text { menahan air minimal } 30 \mathrm{~cm} \\
\text { Lebar caren minimum } 1,5 \mathrm{~m} \\
\text { dengan kedalaman minimum } 0,5 \mathrm{~m} \\
\text { Pintu air masuk dan keluar dibuat } \\
\text { terpisah } \\
\text { Dasar caren miring ke arah } \\
\text { pengeluaran }\end{array}$ & Ordinal \\
\hline & & 3) & $\begin{array}{l}\text { Pemilihan Benih } \\
\text { Ikan }\end{array}$ & 1) & $\begin{array}{l}\text { Berasal dari benih ikan bersertifikat } \\
\text { Benih ikan sehat, tahan hama dan } \\
\text { penyakit } \\
\text { Benih mempunyai daya adaptasi } \\
\text { tinggi } \\
\text { Mempunyai potensi produksi tinggi }\end{array}$ & Ordinal \\
\hline & & 4) & $\begin{array}{l}\text { Pemilihan Benih } \\
\text { Padi }\end{array}$ & $\begin{array}{l}\text { 1) } \\
\text { 2) } \\
\text { 3) } \\
\text { 4) }\end{array}$ & $\begin{array}{l}\text { Berasal dari varietas unggu } \\
\text { Tahan hama dan penyakit } \\
\text { Benih bersertifikat } \\
\text { Potensi produksi tinggi }\end{array}$ & Ordinal \\
\hline & & 5) & $\begin{array}{l}\text { Penggunaan } \\
\text { Sistem Minapadi }\end{array}$ & $\begin{array}{l}\text { 2) } \\
\text { 3) }\end{array}$ & $\begin{array}{l}\text { Sistem penyelang, tumpangsari dan } \\
\text { palawija } \\
\text { Model jajar legowo } \\
\text { Model kolam dalam }\end{array}$ & Ordinal \\
\hline & & 6) & Pengelolaan air & $\begin{array}{l}\text { 1) } \\
\text { 2) } \\
\text { 3) } \\
\text { 4) }\end{array}$ & $\begin{array}{l}\text { Suhu } 25-31^{\circ} \mathrm{C} \\
\text { pH } 5-8 \\
\text { Monitoring parameter kualitas air } \\
\text { Pengamatan pematang sawah } \\
\text { secara rutin }\end{array}$ & Ordinal \\
\hline & & 7) & Pemberian & 1) & $\begin{array}{l}\text { Pemberian pakan disebarkan secara } \\
\text { perlahan }\end{array}$ & Ordinal \\
\hline
\end{tabular}




$\begin{array}{lll}\text { Pakan } & \text { 2) } & \text { Pakan berkualitas dan kandungan } \\ & \text { gizi sesuai } \\ & \text { 3) } & \text { Memiliki nomor } \\ & \text { pendaftaran/sertifikat } \\ & \text { 4) } & \text { Diberikan maksimal 3\% dari total } \\ & \text { biomassa }\end{array}$

Tabel 4. Operasionalisasi Variabel Peran Penyuluh

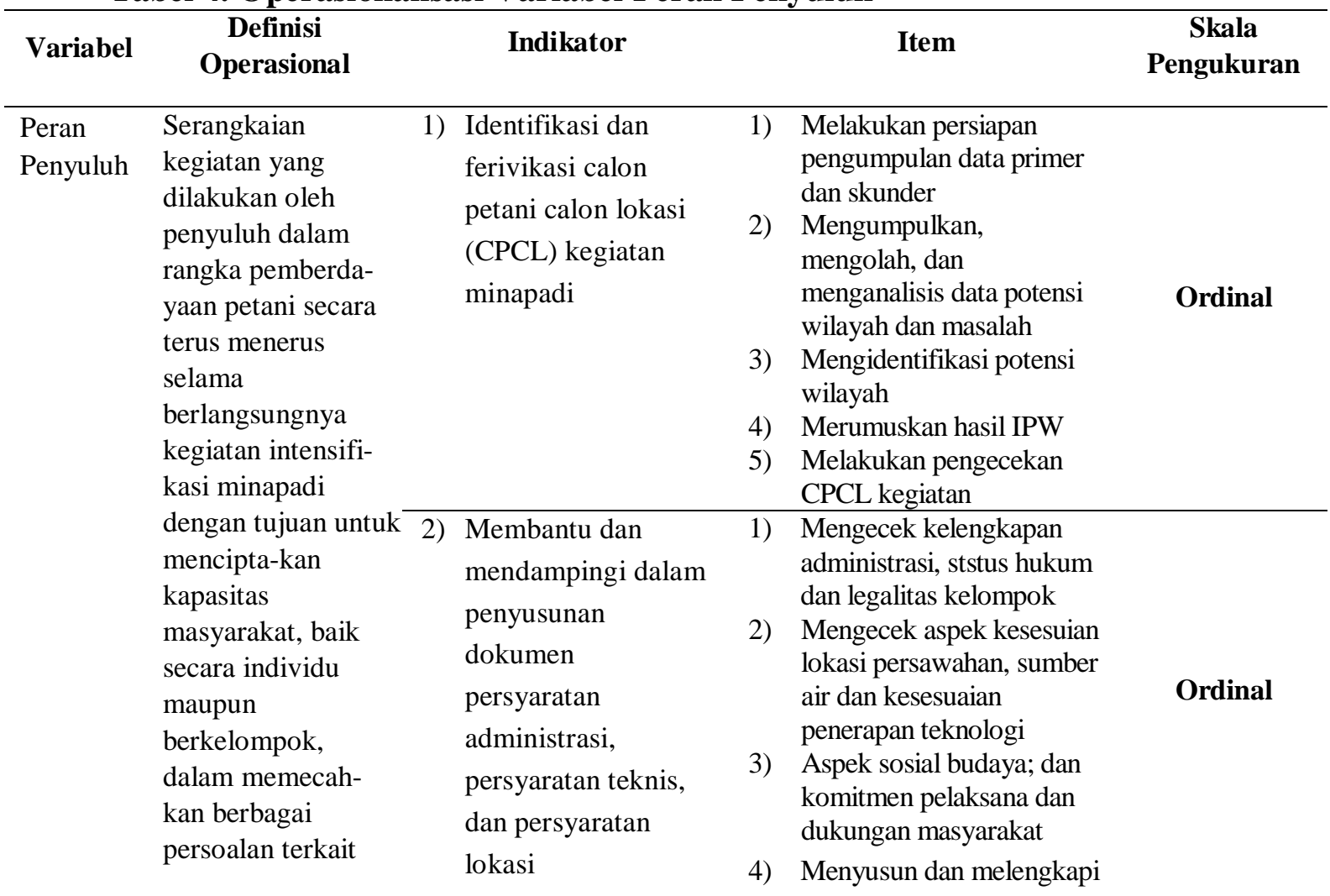


upaya peningkatan kualitas hidup, kemandirian dan kesejahteraannya

\begin{tabular}{|c|c|c|c|c|}
\hline & & 5) & $\begin{array}{l}\text { dokumen kegiatan } \\
\text { Menyampaikan proposal } \\
\text { kepada koordinator teknis } \\
\text { kabupaten }\end{array}$ & \\
\hline 3) & $\begin{array}{l}\text { Mengadakan } \\
\text { pelatihan, bimbingan } \\
\text { teknis dan } \\
\text { manajemen usaha }\end{array}$ & $\begin{array}{l}\text { 6) } \\
7)\end{array}$ & $\begin{array}{l}\text { Mengadakan pertemuan } \\
\text { sekolah lapang } \\
\text { Membimbing dalam } \\
\text { perumusan SID } \\
\text { Menyusun jadwal } \\
\text { pelaksanaan } \\
\text { Membimbing dalam } \\
\text { penyusunan RUK } \\
\text { Mengikuti musyawarah } \\
\text { pembentukan tim } \\
\text { pelaksana dan pengawas } \\
\text { Menyusun perencanaan } \\
\text { Membantu proses } \\
\text { pembukuan }\end{array}$ & Ordinal \\
\hline 4) & $\begin{array}{l}\text { Membantu } \\
\text { memfasilitasi } \\
\text { kemudahan akses } \\
\text { terhadap sarana } \\
\text { produksi, teknologi, } \\
\text { dan pasar, } \\
\text { permodalan serta } \\
\text { keberlanjutan } \\
\text { kegiatan }\end{array}$ & 1) & $\begin{array}{l}\text { Membantu menunjukkan } \\
\text { terhadap pasar input } \\
\text { Membantu menyusun RUK } \\
\text { dan sumber permodalan } \\
\text { Memberikan informasi } \\
\text { terkait inovasi teknologi } \\
\text { Membantu akses terhadap } \\
\text { pasar output } \\
\text { Membuat komitmen dan } \\
\text { rencana budidaya musim } \\
\text { berikutnya } \\
\text { Memberikan motivasi } \\
\text { untuk melanjutkan } \\
\text { minapadi pada musim } \\
\text { berikutnya }\end{array}$ & Ordinal \\
\hline 5) & $\begin{array}{l}\text { Membantu } \\
\text { memecahkan } \\
\text { permasalahan }\end{array}$ & 1) & $\begin{array}{l}\text { Mengidentifikasi sumber } \\
\text { permasalahan } \\
\text { Mengidentifikasi alternatif } \\
\text { pemecahan masalah } \\
\text { Memberikan solusi } \\
\text { pemecahan masalah }\end{array}$ & Ordinal \\
\hline 6) & $\begin{array}{l}\text { Membantu } \\
\text { kelompoktani dalam } \\
\text { membuat laporan } \\
\text { pemanfaatan dana }\end{array}$ & 4) & $\begin{array}{l}\text { Membimbing laporan } \\
\text { perkembangan } \\
\text { Menyusun laporan } \\
\text { perkembangan kegiatan } \\
\text { Memberikan bimbingan } \\
\text { teknis perkembangan } \\
\text { Memeriksa kelengkapan } \\
\text { laporan perkembangan } \\
\text { Memastikan bahan laporan } \\
\text { sampai ke kabupaten } \\
\end{array}$ & Ordinal \\
\hline 7) & $\begin{array}{l}\text { Membuat laporan } \\
\text { hasil pelaksanaan } \\
\text { pendampingan }\end{array}$ & $\begin{array}{l}\text { 1) } \\
\text { 2) } \\
\text { 3) }\end{array}$ & $\begin{array}{l}\text { Mekanisme pelaporan } \\
\text { Frekuensi pelaporan } \\
\text { Alu pelaporan }\end{array}$ & Ordinal \\
\hline
\end{tabular}

Menyampaikan proposal kepada koordinator teknis Mengadakan pertemuan ekolah lapang

Menyusun jadwal pelaksanaan penyusunan RUK pembentukan tim pelaksana dan pengawas

6) Menyusun perencanaan Membantu menunjukkan terkait inovasi teknologi

Membantu akses terhadap Membuat komitmen dan rencana budidaya musim kutnya untuk melanjutkan minapadi pada musim berikutnya Mengidentifikasi alternatif mecahan masalah

Membimbing laporan perkembangan kegiatan

Memberikan bimbingan laporan perkembangan

Memastikan bahan laporan

3) Alu pelaporan 
Data yang dikumpulkan terdiri dari data primer dan data sekunder. Data primer diperoleh dari hasil wawancara langsung dengan petani Sedangkan data sekunder diperoleh dari sumber-sumber data lainnya diantaranya hasil studi pustaka, instansiinstansi atau bahan publikasi yang dikeluarkan lembaga-lembaga yang ada hubungannya dengan penelitian ini.

Pengambilan responden dilakukan dengan menggunakan metode sensus, yaitu dengan mengambil seluruh petani yang mengelola sistem pertanian terpadu intensifikasi minapadi yang tergabung dalam Kelompoktani Mulyasari di Desa Arjasari Kecamatan Leuwisari berjumlah 45 orang. Hal ini sejalan dengan pendapat Arikunto (2010) yang menyatakan apabila subjeknya kurang dari 100 lebih baik diambil semua. Sebaliknya jika subjeknya lebih besar dari 100 dapat diambil antara 10 sampai 15 persen, 20 sampai 25 persen atau lebih.

Teknik analisis data yang akan digunakan untuk mengetahui peran penyuluh dan intensifikasi minapadi Kelompoktani Mulyasari Desa Arjasari Kecamatan Leuwisari pada penelitian ini adalah menggunakan teknik analisis kualitatif dengan skala pengukuran interval tipe skala likert. Skor variabel peran penyuluh dibedakan dalam lima kategori, yaitu : (1) tidak berperan; (2) kurang berperan, (3) cukup berperan; (4) berperan; dan (5) sangat berperan dan (1) selalu, (2) sering, (3) kadang-kadang, (4) jarang dan (5) tidak pernah.

Untuk mengetahui pengaruh peran penyuluh, umur, pendidikan, pengalaman, jumlah keluarga, luas lahan, akses terhadap pasar input, akses terhadap pasar output pendapatan dan keikutsertaan dalam kelompoktani terhadap tingkat penerapan intensifikasi minapadi pada Kelompoktani Mulyasari di Desa Arjasari Kecamatan Leuwisari Kabupaten Tasikmalaya dianalisis dengan menggunakan uji Regresi Linear Berganda.

Berdasarkan faktor-faktor yang diduga mempengaruhinya, maka model regresi liner berganda dapat dirumuskan sebagai berikut :

$$
\begin{gathered}
Y=\beta_{0}+\beta_{1} X_{1}+\beta_{2} X_{2}+\beta_{3} X_{3}+ \\
\beta_{4} X_{4}+\beta_{5} X_{5}+\beta_{6} X_{6}+\beta_{7} X_{7}+\beta_{8} X_{8}+ \\
\beta_{9} X_{9}+\beta_{10} X_{10}
\end{gathered}
$$

Dimana :

$\mathrm{Y} \quad=$ Intensifikasi minapadi

$\beta_{0} \quad=$ Intersep

$\beta_{1}=$ Parameter peubah $\mathrm{X}$

$\mathrm{X}_{1} \quad=$ Peran Penyuluh

$\mathrm{X}_{2}=$ Umur (tahun)

$\mathrm{X}_{3} \quad=$ Pengalaman (tahun)

$\mathrm{X}_{4} \quad=$ Pendidikan (tahun)

$\mathrm{X}_{5} \quad=$ Jumlah tanggungan keluarga (jiwa) 
$\mathrm{X}_{6} \quad=$ Keikutsertaan dalam

kelompoktani

$\mathrm{X}_{7} \quad=$ Pendapatan (Rp)

$\mathrm{X}_{8} \quad=$ Luas lahan (ha)

$\mathrm{X}_{9} \quad=$ Akses ke pasar input $(\mathrm{Km})$

$\mathrm{X}_{10}=$ Akses ke pasar output $(\mathrm{Km})$

Uji F dilakukan untuk mengetahui pengaruh variabel bebas (x) secara keseluruhan terhadap variabel terikat (y) . Uji $\mathrm{t}$ digunakan untuk mengetahui pengaruh secara parsial masing-masing variabel bebas (xi) terhadap variabel terikat (y). Koefisien Determinasi $\left(\mathrm{R}^{2}\right)$ menunjukkan seberapa besar keseluruhan model dalam menerangkan nilai variabel terikat.

\section{HASIL DAN PEMBAHASAN}

\section{Peran Penyuluh}

Tabel 5. Nilai Indikator Peran Penyuluh

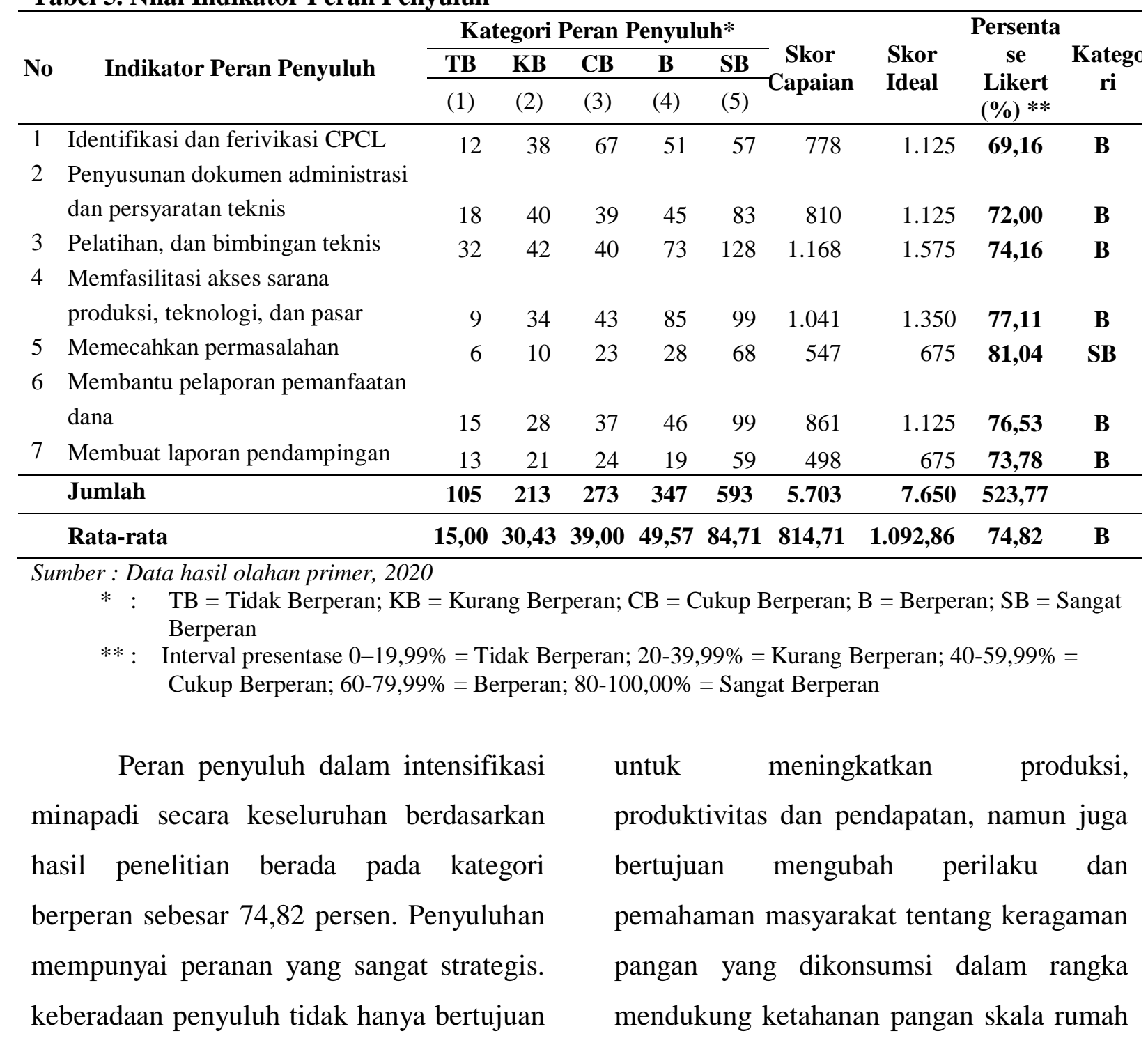


tangga hingga tingkat nasional. Menurut Padmowiharjo (2006), kehadiran dan peranan penyuluh di tengah masyarakat masih sangat dibutuhkan untuk meningkatkan kualitas sumber daya manusia sehingga mampu mengelola sumber daya alam yang ada secara intensif demi tercapainya peningkatan produktivitas dan pendapatan.

Penyuluh telah berusaha membangkitkan partisipasi petani melalui kesukarelaan, keterlibatan dalam pengambilan keputusan, keterlibatan dalam pelaksanaan kegiatan, keterlibatan dalam kegiatan evaluasi, keterlibatan dalam pemanfaatan, dan pelaporan. Usaha penyuluh bekerjasama dengan tokoh masyarakat dan pengurus kelompoktani dalam menjalankan perannya. Sehingga peran tersebut berhasil memberikan pengaruh positif terhadap pencapaian kemandirian pangan petani pada Kelompoktani Mulyasari Desa Arjasari melalui intensifikasi minapadi

\section{Intensifikasi Minapadi}

Tabel 6. Nilai Indikator Intensifikasi Minapadi

\begin{tabular}{|c|c|c|c|c|c|c|c|c|c|c|}
\hline \multirow[b]{2}{*}{ No } & \multirow{2}{*}{$\begin{array}{c}\text { Indikator Intensifikasi } \\
\text { Minapdi }\end{array}$} & \multicolumn{5}{|c|}{ Kategori Intensifikasi Minapdi* } & \multirow{2}{*}{$\begin{array}{l}\text { Skor } \\
\text { Capaian }\end{array}$} & \multirow{2}{*}{$\begin{array}{l}\text { Skor } \\
\text { Ideal }\end{array}$} & \multirow{2}{*}{$\begin{array}{c}\text { Persentase } \\
\text { Likert }(\%) \\
* *\end{array}$} & \multirow[b]{2}{*}{ Kategor } \\
\hline & & $\begin{array}{l}\mathbf{T P} \\
(1)\end{array}$ & $\begin{array}{c}\mathbf{J} \\
(2)\end{array}$ & $\frac{\text { Kd }}{(3)}$ & $\begin{array}{l}\mathbf{S r} \\
(4)\end{array}$ & $\begin{array}{c}\text { Sl } \\
(5)\end{array}$ & & & & \\
\hline 1 & Persiapan lahan & 12 & 17 & 21 & 64 & 66 & 695 & 900 & 77,22 & $\mathrm{Sr}$ \\
\hline 2 & Pembuatan wadah minapadi & 10 & 16 & 21 & 63 & 115 & 932 & 1.350 & 69,04 & $\mathrm{Sr}$ \\
\hline 3 & Pemilihan benih ikan & 15 & 6 & 20 & 43 & 96 & 739 & 900 & 82,11 & Sl \\
\hline 4 & Pemilihan benih padi & 11 & 16 & 12 & 57 & 84 & 727 & 900 & 80,78 & $\mathrm{~S} 1$ \\
\hline 5 & Penggunaan sistem & 7 & 14 & 19 & 26 & 69 & 541 & 675 & 80,15 & S1 \\
\hline 6 & Pengelolaan air & 8 & 11 & 33 & 39 & 89 & 730 & 900 & 81,11 & $\mathrm{~S} 1$ \\
\hline 7 & Pemberian pakan & 11 & 9 & 16 & 69 & 75 & 728 & 900 & 80,89 & S1 \\
\hline 8 & Panen & 23 & 19 & 34 & 58 & 91 & 850 & 1.125 & 75,56 & $\mathrm{Sr}$ \\
\hline 9 & Pengemasan & 15 & 8 & 20 & 59 & 78 & 717 & 900 & 79,67 & $\mathrm{Sr}$ \\
\hline & Jumlah & 112 & 116 & 196 & 478 & 763 & 6.659 & 8.550 & 706,52 & \\
\hline & Rata-rata & 12,44 & 12,89 & 21,78 & 53,11 & 84,78 & 739,89 & 950,00 & 78,50 & $\mathrm{Sr}$ \\
\hline
\end{tabular}

Sumber : Data hasil olahan primer, 2020

* : $\mathrm{TP}=$ Tidak Pernah; J = Jarang; Kd = Kadang-kadang; Sr = Sering; Sl = Selalu

** : Interval presentase 0-19,99\% = Tidak Pernah; 20-39,99\% = Jarang; $40-59,99 \%=$ Kadang-kadang; 60-79,99\% = Sering; $80-100,00 \%=$ Selalu

Penerapan komponen inti intensifikasi minapadi secara keseluruhan berdasarkan hasil penelitian berada pada kategori selalu diterapkan sebesar 78,50 persen. Muali dari persiapan lahan hingga panen dan pascapanen. Persiapan lahan minapadi dilakukan beragam oleh petani. ada yang dilakukan secara intensif, tanah 
diolah dua kali, diberi tambahan pupuk dan obat serta vitamin sementara yang sederhana dilakukan tanpa perlakuan apapun. Menurut Sudirman dan Setiawan (1999), apabila pengolahan tanah tempat minapadi dilakukan tidak sempurna maka pertumbuhan tanaman padi dan ikan minapadi menjadi terganggu.

\section{Faktor-faktor yang Mempengaruhi Intensifikasi Minapadi}

Hasil olah data untuk ANOVA menunjukkan nilai $\mathrm{F}$ (Value) $=2,846$ dengan nilai $\mathrm{P}($ Prob $>\mathrm{F})$ atau signifikansi $0,011^{\mathrm{a}}$, secara statistik karena $\mathrm{P}<\alpha=0,05$ $(0,011<0,05)$. maka penafsiran yang lain dapat dilakukan dengan menggunakan model regresi ini. Artinya secara simultan terdapat pengaruh faktor peran penyuluh, umur, pengalaman, tingkat pendidikan, jumlah keluarga, keikutsertaan dalam kelompoktani, pendapatan, luas lahan, akses ke pasar input dan akses ke pasar output terhadap intensifikasi minapadi pada Kelompoktani Mulyasari. Hal ini sejalan dengen Sujaya, et. al., (2018); bahwa karakteristik sosial ekonomi dan lingkungan petani berpengaruh terhadap adopsi dan produktivitas minapadi. Nilai koefisien determinasi $\left(\mathrm{R}^{2}\right)$ sebesar 0,456. Artinya 45,6 persen intensifikasi minapadi dapat dijelaskan oleh variabel faktor penduga, sedangkan sisanya 54,4 persen dipengaruhi oleh variabel lain yang tidak dimasukkan ke dalam model penelitian ini.

\begin{tabular}{lrrrrrr}
\multicolumn{7}{c}{ ANOVA $^{\mathbf{b}}$} \\
\hline Model & Sum of Squares & df & Mean Square & F & Sig. \\
\hline 1 Regression & .638 & 10 & .064 & 2.846 & $.011^{\mathrm{a}}$ \\
Residual & .762 & 34 & .022 & & \\
Total & 1.401 & 44 & & & \\
\hline
\end{tabular}

a. Predictors: (Constant), Akses ke Pasar Output, Keikutsertaan Poktan, Tingkat Pendidikan, Peran Penyuluh, Pendapatan, Jumlah Keluarga, Pengalaman, Akses ke Pasar Input, Umur, Luas Lahan

a. Dependent Variable: Intensifikasi Minapadi

\begin{tabular}{|c|c|c|c|c|c|}
\hline \multicolumn{6}{|c|}{ Model Summary ${ }^{b}$} \\
\hline Model & $\mathbf{R}$ & R Square & $\begin{array}{c}\text { Adjusted R } \\
\text { Square }\end{array}$ & $\begin{array}{c}\text { Std. Error of the } \\
\text { Estimate }\end{array}$ & $\begin{array}{l}\text { Durbin- } \\
\text { Watson }\end{array}$ \\
\hline 1 & $.675^{\mathrm{a}}$ & .456 & .296 & .14974 & 1.714 \\
\hline
\end{tabular}

Untuk mengetahui pengaruh parsial dilakukan analisis uji t. Nilai t test 
digunakan dalam pengujian terhadap $\mathrm{X}_{10}$. variabel independent $X_{1}$ sampai dengan

\begin{tabular}{|c|c|c|c|c|c|}
\hline \multicolumn{6}{|c|}{ Coefficients $^{\mathrm{a}}$} \\
\hline & \multirow{2}{*}{ Model } & \multicolumn{2}{|c|}{ Unstandardized Coefficients } & \multirow[t]{2}{*}{$\mathbf{t}$} & \multirow[t]{2}{*}{ Sig. } \\
\hline & & B & Std. Error & & \\
\hline \multirow[t]{11}{*}{1} & (Constant) & 3.103 & .387 & 8.021 & .000 \\
\hline & Peran Penyuluh & -.033 & .089 & -.365 & .718 \\
\hline & Umur & .015 & .004 & 4.120 & .000 \\
\hline & Pengalaman & -.006 & .004 & -1.327 & .193 \\
\hline & Tingkat Pendidikan & .033 & .010 & 3.179 & .003 \\
\hline & Jumlah Keluarga & -.010 & .026 & -.383 & .704 \\
\hline & Keikutsertaan Poktan & -.041 & .052 & -.781 & .440 \\
\hline & Pendapatan & 3.975 & .000 & 2.101 & .043 \\
\hline & Luas Lahan & -.682 & .294 & -2.316 & .027 \\
\hline & Akses ke Pasar Input & -.047 & .044 & -1.071 & .292 \\
\hline & Akses ke Pasar Output & .096 & .037 & 2.605 & .014 \\
\hline
\end{tabular}

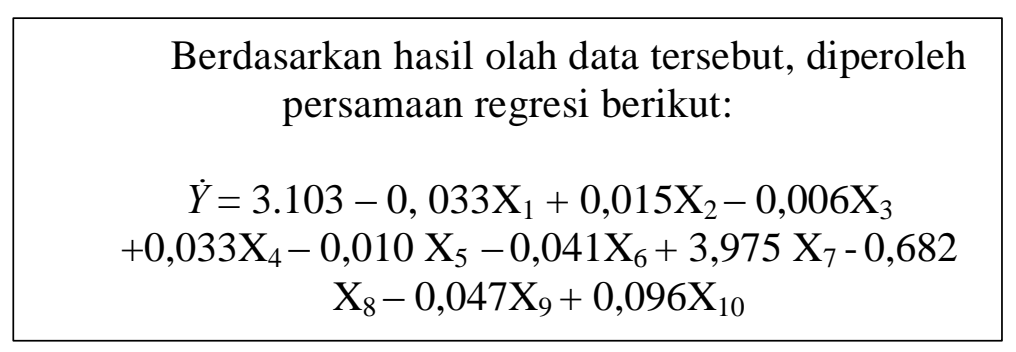

Nilai $t_{\text {hitung }}$ variabel peran penyuluh sebesar $-0,365$ dan probabilitas sebesar $0,718(0,718>0,05)$, maka Ho diterima dan Ha diterima yang berarti tidak terdapat pengaruh antara variabel peran penyuluh terhadap intensifikasi minapadi pada Kelompoktani Mulyasari.

Nilai $t_{\text {hitung }}$ pada variabel jarak ke pasar input sebesar -1,071 dan probabilitas sebesar 0,292 (0,292>0,05), maka Ho diterima dan Ha ditolak. Nilai $t_{\text {hitung }}$ pada variabel jumlah keluarga sebesar $-0,383$ dan probabilitas sebesar $0,704(0,704>0,05)$, maka Ho diterima dan Ha ditolak.

Nilai $t_{\text {hitung }}$ pada variabel keikutsertaan dalam kelompoktani sebesar $-0,781$ dan probabilitas sebesar 0,446 $(0,446>0,05)$, maka Ho diterima dan $\mathrm{Ha}$ ditolak. maka Ho diterima dan Ha ditolak yang berarti tidak terdapat pengaruh antara keikutsertaan dalam poktan terhadap 
intensifikasi minapadi pada Kelompoktani Mulyasari

Nilai $t_{\text {hitung }}$ pada variabel umur sebesar 4,120 dan probabilitas sebesar $0,000(0,000<0,05)$, maka Ho ditolak dan Ha diterima yang berarti terdapat pengaruh antara variabel umur terhadap intensifikasi minapadi.

Nilai $t_{\text {hitung }}$ pada variabel luas lahan sebesar -2,316 dan probabilitas sebesar $0,027(0,026<0,05)$, maka Ho ditolak dan Ha diterima. Nilai $t_{\text {hitung }}$ variabel jarak ke pasar output sebesar 2,605 dan probabilitas sebesar $0,014 \quad(0,014<0,05)$, maka Ho ditolak dan $\mathrm{Ha}$ diterima yang berarti terdapat pengaruh jarak ke pasar terhadap intensifikasi minapadi pada Kelompoktani Mulyasari

\section{KESIMPULAN DAN SARAN}

\section{kesimpulan}

1) Peran penyuluh dalam melakukan pendampingan intensifikasi minapadi pada Kelompoktani Mulyasari Desa Arjasari Kecamatan Leuwisari Kabupaten Tasikmalaya berada pada kategori berperan sebesar 74,82\%.

2) Intensifikasi komponen minapadi pada Kelompoktani Mulyasari Desa Arjasari Kecamatan Leuwisari Kabupaten Tasikmalaya secara keseluruhan berada pada kategori selalu diterapkan sebesar $78,50 \%$.

3) Faktor yang berpengaruh terhadap intensifikasi minapadi pada Kelompoktani Mulyasari Desa Arjasari Kecamatan Leuwisari adalah umur, tingkat pendidikan, pendapatan, luas lahan, dan akses ke pasar output. Sementara faktor peran penyuluh, pengalaman, jumlah keluarga, keikutsertaan dalam kelompoktani dan akses ke pasar input tidak memberikan pengaruh nyata.

\section{Saran}

1) Penyuluh harus lebih berperan dalam mendorong petani agar tetap melakukan intensifikasi minapadi karena terbukti memberikan manfaat dan keuntungan bagi petani

2) Untuk mempercepat proses adopsi teknologi minapadi, seyogyanya sistem teknologi ini selalu digalakkan karena merupakan salah satu solusi dalam menjawab persoalan ekonomi dan kebutuhan gizi dan nutrisi masyarakat serta upaya mewujudkan ketahanan pangan pada skala rumah tangga

3) Perlu dilakukan penelitian lebih lanjut terkait dengan faktor yang berpengaruh terhadap intensifikasi dilihat dari aspek lain. 


\section{DAFTAR PUSTAKA}

Abuasir, S., Hakim, N., \& Sumitro, Y. 2004. Faktor-faktor yang Mempengaruhi Adopsi Sistem Usahatani Minapadi di Desa Pujo Rahayu Kecamatan Belitang Kabupaten OKU. Jurnal Komunikasi dan Pengembangan Masyarakat, 1(1) : 30-37.

Arikunto, S. 2010. Prosedur Penelitian Suatu Pendekatan Praktik. Rineka Cipta, Jakarta.

Das, A. 2013. Integrated Farming: An Approach to Boost up Family Farming. LEISA India. Vol 15 (4) : 56-61.

Diodenha, A. 2011. Persepsi Lingkungan Petani Desa Purwasari, Kec. Dramaga, Kab. Bogor terhadap Penerapan Teknologi Intensifikasi Minapadi (INMIDI). Skripsi. IPB. Tidak Dipublikasikan.

Nurhayati, A., Lili, W., Herawati, T., \& Riyantini, I. 2016. Derivatif Analysis of Economic and Social Aspect of Added Value Minapadi
(Paddy-fish Integrative Farming) a Case Study in the Village of Sagaracipta Ciparay Sub District, Bandung West Java Province, Indonesia. Aquatic Procedia, 7, pp: 12-18.

Padmowiharjo S. 2006. Penyuluhan Pendampingan Partisipatif. Jurnal Penyuluhan 2:63-64.

Sudirman dan Setiawan. AI. 1999. Mina Padi Budi Daya Ikan Bersama Padi. Penebar Swadaya, Jakarta.

Sugiyono. 2013. Metode Penelitian Pendidikan Pendekatan Kuantitatif, Kualitatif dan $R \& D$. Alfabeta, Bandung.

Sujaya, D.H, Hardiyanto, T. Isyanto, A.Y. 2018. Faktor-faktor yang Berpengaruh terhadap Produktivitas Usahatani Mina Padi di Kota Tasikmalaya. MIMBAR AGRIBISNIS. 2018. 4(1): 25-39.

Surtida, A. P. 2000. Rice-Fish Culture Systems. SEAFDEC Asian Aquaculture, XXII (6), pp:22-23. 